\title{
Implementing the Flipped Classroom in an Undergraduate Corporate Finance Course
}

\author{
Jayendra S. Gokhale \\ Correspondence: Jayendra S. Gokhale, David B. O'Maley College of Business, Embry-Riddle Aeronautical University, 1 \\ Aerospace Blvd., Daytona Beach, USA.
}

Received: Sep. 24, 2020

doi:10.11114/ijce.v4i1.5026
Accepted: Oct. 30, $2020 \quad$ Online Published: Nov. 12, 2020

URL: https://doi.org/10.11114/ijce.v4i1.5026

\begin{abstract}
This study analyzes flipped mode of instruction in Corporate Finance. In the current environment, with many students in quarantine and greater emphasis on self-study, it is even more relevant to understand how students understand and retain concepts derived from online environment. In this study, performance of students in flipped mode is compared with the performance in traditional lecture-style. In flipped class, students watched a brief video-lecture, took an online assessment quiz prior to attending an interactive discussion-based class session, unlike the traditional lecture style. The results of this study suggest that with flipped mode, most students take greater responsibility of their learning, prefer hands-on learning, achieve more and feel more satisfied with their performance. However, there is no statistical difference in the test scores of students in the flipped classroom as compared to the traditional classroom.
\end{abstract}

Keywords: flipped classroom, corporate finance, higher education

\section{Introduction}

Direct instructional techniques, such as lectures, can benefit some types of student learning. However, other instructional strategies are needed for students to learn how to apply concepts accurately. This is particularly relevant in an environment when students need to take greater responsibility of their work, such as during a pandemic. Through lecturing, faculty can communicate the structure of knowledge (Bligh, 2000). However, helping students understand how knowledge is structured benefits students' ability to organize their own understanding of new concepts and learn how these concepts relate to each other (Ambrose et. al, 2010). Furthermore, as an instructional strategy, lecturing does not provide students with opportunities to practice applying these newly learned theoretical knowledge. Additionally, in order to form accurate conceptual understanding, students need frequent and corrective feedback about their efforts to apply concepts. Since traditional lecturing does not usually provide either practice of application or corrective feedback, other instructional strategies are needed to give students opportunities to retrieve, apply, and correct their conceptual understanding. One instructional strategy that supports student learning for an accurate application of concepts is the flipped classroom, particularly when supported by online lectures and assessments (Mu and Paparas, 2016).

The flipped classroom has been publicized as an effective instructional method that can complement the traditional lecture. In a flipped classroom, students spend time engaged in direct instruction prior to attending the class (rather than in class itself). Direct instruction activities may require students to listen to a lecture, read articles or review sections of the textbook. After engaging in direct instruction activities, the students arrive in their class prepared to apply the concepts and receive feedback on their conceptual knowledge structures. By preparing students with an introduction to the course concepts such as homework activities, instructors have time during the class to engage students in applying their learning. The time students spend with their instructor in class can then be used to apply and expand students' conceptual understanding. While this instruction strategy has been widely studied in many areas such as medicine, engineering and economics, there is need for research in measurement of application of this instructional strategy in Finance.

\section{Review of Relevant Literature}

Conventional classroom instruction in Corporate Finance is limited to the delivery of a lecture based on theoretical concepts, and if time permits then administer an activity based on problem solving. For example, an activity on the Internal Rate of Return (IRR) may contain all projects in the chapter of the text, that are analyzed using the Net Present Value (NPV) method to analyze which project can yield the best IRR. However, the activity may also reveal that the 
project with best NPV may not be a great project for an investor. When students participate in these activities, they are able to apply their understanding to real world problems and analyze the theoretical concepts. This conforms to the third level (analysis) and the fourth level (evaluation) described by Bloom et al. (1956), that allows students to analyze a real-world application with theoretical concepts they learned and then evaluate the best course of action based on this analysis. However, only if students are able to synthesize these concepts into higher order applications, such as research projects, do they go beyond the content taught in a standard classroom. Research projects provide the flexibility to students, to study problems of their choice, and dig deeper into application of concepts to the real world.

While researchers are still divided about the exact definition of "flipped", most literature that is discussed in this section agrees that this instructional strategy involves introduction of basic concepts outside the classroom. This is particularly important when greater emphasis is placed on students taking responsibility of their own learning. The credit of pioneering flipped learning methodology in an online lecture format is given to two Colorado high school teachers Jonathan Bergman and Aaron Sams. They used video lectures by employing the screen-capture method to help those students who missed class. However, they discovered that this helped other students who were present in class as well. This led them to recreate new activities for in-class learning (Bergmann and Sams, 2009). The number of instructors adopting the flipped classroom method is growing rapidly. Ninety-six percent of instructors who have used the flipped approach recommend it to others (Sophia, 2014).

Research on flipped classroom method of instruction has ranged from measuring test scores and/or collecting surveys (Bishop and Verleger, 2013). The concept of flipped (or inverted) classroom is not relatively new. The case study approach has long been taught in business schools using a similarly inverted method. Students are expected to read the case ahead of time, answer questions related to the case, and then discuss in class. Theoretical concepts are also illustrated through discussion. However, measuring the performance of students in an inverted classroom has always been a challenge. That is what this study attempts to perform.

It is commonly believed that the undergraduate student today spends most of the time on social media such as YouTube $^{\circledR}$, and learns by listening rather than reading, especially with the advent of audio books and YouTube ${ }^{\circledR}$ (Hao, 2016). More than half the students are connected to the college/university network through at least two devices at the same time (Dahlstrom et al., 2014). One way to address this style of learning is to place more emphasis on online learning. However, as Fendler et al. (2011) found, lower level learning by students in an online set-up is not significantly different from lower level learning by students in the traditional classroom. But in order to encourage students to engage in higher level learning, a traditional set-up is required. The flipped classroom fits all of these requirements and is thus a topic of enquiry at the cutting edge of education research.

On one hand, student learning in the flipped classroom breaks away from the traditional mold of lecture-based assessment technique followed in most classrooms and caters to the student of today who wants to decide when to listen to specific content. However, on the other hand, the flipped class invites trouble for the instructor by putting the onus of learning on the students themselves. Students are required to go through the content at their convenience before class and come prepared to class for higher level activities, which were traditionally carried out at home. Thus, flipped classroom removes the spotlight from the instructor, and puts the students at the forefront through active learning (Toto and Nguyen, 2009). Consequently, student learning from the lecture occurs either online, or through notes provided by the instructor, followed by a quick assessment quiz. These activities are in preparation for subsequent active learning. In the classroom, students are exposed to hands-on problem solving, which induces higher order of learning (Berrett, 2012).

Findlay-Thompson et al. (2014) studied the survey responses of students in an undergraduate business course in the section that used flipped style of learning and compared these responses with students in sections that did not use the style. They found that student views about flipped class were mixed, and the performance of students in exams in the flipped class was not significantly different from that in the traditional lecture style classroom. Crouch and Mazur (2001) and Mazur (2009) used the inverted classroom and peer instruction methodology using clickers and found that better student performance on assessment quizzes is linked with students learning from each other. Lape et al. (2014) looked at an inverted classroom while teaching engineering and math and found a significant difference in student performance on assessment tests, when comparing a traditional class with an inverted class. Lage et al. (2000) use the inverted format of instruction in the Principles of Economics class and find greater student understanding of concepts. They also found that female students tend to outperform their male counterparts in the inverted format.

The flipped classroom has been studied in several other subjects. Alan Eager et al. (2014) used the flipped classroom approach in teaching a mathematical biology class for life science majors. Kaner and Fiedler (2014) described the implementation of the flipped classroom in a computer science class on software testing. Butt (2014) discussed the implementation of the flipped classroom and in an actuarial studies class using survey-based methodology. In these 
flipped or inverted classroom studies, researchers have examined either student attitudes or student performance in assessment tests. Talbert (2014) discussed the implementation of flipped classroom in a linear algebra class and found that $70 \%$ students prefer a fully inverted approach, while most of the remaining $30 \%$ prefer peer to peer learning.

Moravec et al. (2010) compared the performance of a biology class under a flipped set-up for select material called learn before lecture (LBL) and compared the performance of students in LBL with the past students in the same class. When comparing students' performance on specific exam questions related to the LBL content, they found that the performance of students had improved significantly in the LBL related content. Bates and Galloway (2012) studied the performance of first-year students enrolled in a physics course. Using the Forced Concept Inventory (FCI) as both the pre-test and post-test, these researchers noticed substantial learning gains by the students when they implemented this in a flipped classroom.

Mason, Shuman, and Cook (2013) reviewed studies about effective strategies to design an inverted classroom in an upper-division engineering course. They then undertook a two-year study to determine how the inverted classroom structure impacted content coverage, student performance on traditional textbook-type problems and student satisfaction rates. They found that the inverted classroom course covered more content throughout the semester than the traditional lecture course. They also found that the inverted classroom students performed better on design problems and on certain problem sets (open-loop analysis, root locus-based design, and Bode plot-based controller design). No significant difference in performance was found in other comparisons.

The study of impact of flipped style of instruction in the area of undergraduate finance is scant (Ağirman and Trinh, 2019). Psihountas (2018) have studied the effect of this style on student learning in MBA classes. From their experience, it is particularly important to note the fact that this style allows students to be prepared for instruction in the classroom by enabling them to carry out background work on their own. This would otherwise lead to significant utilization of class time on concepts, which can otherwise be imbibed by students at their own convenience and pace. Thus, the onus of learning starts at home with prior preparation. This study contributes to the existing literature by comparing and contrasting the experiences, and the performance on tests of students in a flipped class of Corporate Finance with that of the students in a traditional class taught by the same instructor at the same point of time. Students in this study are exposed to almost identical course content. However, in the traditional class, video lectures and assessment quizzes were neither provided before class nor enforced afterward. The findings of this study are in line with those of Andreychik \& Martinez (2019), where there is no statistical difference in performance of students taught in the flipped mode as compared to the traditional style.

\section{Background}

This study assesses the performance and the feedback of students in the Corporate Finance I (hereafter just Corporate Finance) class at the undergraduate level. Students in this class are typically not at the freshman level. Students are required to successfully complete a course in Financial Accounting (hereafter just Accounting) before registering for this class. The benefit of the Accounting class is that students can understand and interpret financial statements better. Financial statements covered in the Accounting class relevant to Corporate Finance are balance sheet, income statement and the statement of cash flows. Corporate Finance class is broadly divided into four parts as follows:

- The first part includes an overview of corporate governance, and of different financial markets (bonds, stocks, futures, options etc.).

- The second part includes description of the stock and the bond markets, and the pricing of stocks and bonds.

- The third part includes project management, which covers net present value, internal rate of return and the relative cost of debt and equity.

- $\quad$ The concepts from all three parts are then used in the final part, which deals with the weighted average cost of capital.

At the university, this class is typically taught in a conventional lecture format, in which students are lectured in class, and are expected to solve problems from the text-book. These problems are often found at the end of each chapter. Moreover, students are also expected to complete quizzes and/or other worksheets prepared by the instructor. In the spring semester of 2015, the author taught four class sections of Corporate Finance. This provided a unique opportunity to evaluate the costs and benefits of the flipped style of learning for students in the Corporate Finance class. One class section was taught using the flipped method and students' learning/performance was measured and compared with the learning/performance of the students in the other three class sections in tests and surveys, which were taught using the conventional lecture-activity style. The author is faculty with prior experience in teaching the target class. 


\section{Methodology}

A part of this study is based on student performance in four class sections of the Corporate Finance class. Three sections met on Monday-Wednesday-Friday (MWF) and one met on a Tuesday-Thursday (TR) schedule. The university does not differentiate between MWF and TR classes. There were 28 students in section 1, of which $21 \%$ were female. There were 32 students in section 2, of which $19 \%$ were female. There were 26 students in section 3, of which $19 \%$ were female. These class sections were taught using the traditional format. The fourth section was taught using the flipped style. There were 32 students in this class section, of which $19 \%$ were female. The students were not aware of the flipped style of instruction at the time of enrollment. However, they were made aware of this in the first class. This news did not have any effect on the enrollment number for this class, even though students are allowed to add or drop a class for up to 2 class sessions in the first week.

As in Moravec et al. (2014), the flipped class section was initially taught using a blended form of the conventional lecture-activity style to get the students acclimatized to the subject and to the overall flipped style. But once the students got familiar with initial topics and the professor's teaching style, students of this section were introduced to the flipped style of learning. Hence, there was conventional lecture on the first Chapter. Gradually, as the students understood the online lectures better, in-class lectures were reduced to discussion of the online lectures. By the time class had completed the third chapter, students were watching lectures at home and solving assessment quizzes on their own.

Prior to this semester, students in Corporate Finance class taught by the author were traditionally provided with only PowerPoint slides to the lecture on the day of the lecture. The PowerPoint slides to each lecture contain keywords and mathematical intuition into each topic being covered. Students also have access to online lectures through the university's Canvas ${ }^{\circledR}$ online learning management system. The lectures were recorded using screen capture software called Captivate sold by Adobe Systems. The video lectures were uploaded to Canvas. Online assignments/quizzes were created in a text editing software and uploaded to Canvas using "Respondus" software.

At the beginning of the semester, students in the flipped class section were made aware that the class would be taught using a flipped format through the course syllabus. In addition, the students were regularly reminded about the lecture to be covered through announcements on Canvas. An approval was obtained from the Institutional Review Board and the students signed a disclaimer form, in which they acknowledged that they were aware that their progress would be monitored for the purpose of research.

All the students in each of the four class sections were given access to the same content on Canvas. However, online lectures and the assessment quizzes were neither available before class, nor were they enforced for the students in the traditional class sections. The students' qualitative feedback and progress in all four class sections was monitored regularly either through online quizzes or through in-class problem solving activities or both. Students worked together on the class activities in teams. They teamed up randomly at the beginning of the semester and stayed in the same team for the rest of the semester. The grade on activities was calculated by grading an individual's activity sheet and assigning the same score to the entire team.

In addition to activities, teams in the flipped class section carried out a research project. In their research project, each team picked up a company of the members' choice and analyzed the financial statements and the most recent events in the company's history. The teams also analyzed an impact of these events on the financial statements.

According to the course syllabus, nine chapters of the textbook Brealey et al. (2007) are covered during the semester. Each chapter contained several video lectures, one or more assessment quiz(zes) and one or more activities depending on the amount and difficulty of the content. Although the quizzes did not have a high weight in the final grade, they served two purposes. First, these quizzes made sure that the students stayed up-to-date with the course schedule. Second, these were meant to help a student evaluate his/her understanding of the course content. Therefore, the quiz questions were directly based on PowerPoint and video lectures and were meant to perform a similar function to the Forced Concept Inventory adopted by Bates and Galloway (2012), by revealing where the students had misconceptions about the content.

As discussed before, the first chapter in the flipped class section was taught in the traditional style. For the second chapter, the students were assigned two online lectures and two at-home quizzes/assignments. The lectures were discussed somewhat at length in class. The assessment quizzes were due after the chapter was taught, in order to ensure that students got used to the style and the wording of the quizzes and were able to identify the connection with online lectures.

Barring the chapters mentioned above, the rest of the syllabus was completed using flipped style of learning. The students were assigned an online lecture and a quiz before each lecture. The quiz was due before class. When the students came to class, they had to take the quiz again, but as a team. The purpose of this was to enable those students 
who did not take the quiz or those who did not understand a concept properly, to catch up with the others, and to stimulate discussion on pertinent questions. The class was then given instructions for an in-class activity. These quizzes and online lectures were also available ahead of time, but not published on Canvas for class sections that were taught in the conventional style.

Besides evaluation through in-class activities, all four class sections were assessed using same mid-term exams and a final exam. The quiz grade for the flipped class section formed a part of the class participation grade, which also included team performance in the class activities. Besides these, the flipped class was also assessed on performance in the research project.

Student feedback was evaluated regularly in all class sections. Additionally, students also responded to a few extra questions in the flipped class through anonymous end-of-semester course evaluation system required by the university. Student feedback is discussed in the "results and discussion" section of this paper. Each midterm (MT) exam: midterm 1(MT1) and midterm 2 (MT2) was 60-minute-long, while the final exam was 1 hour and 50-minutes long. Quantitative analysis was carried out by performing an unpaired mean comparison test while testing the statistical significance of the difference.

In the mean comparison test, we describe $x_{i} \forall i=1 \ldots n_{x}$, where $x_{i}$ is the score obtained by a student $i$ in section 4 on a test and $n_{x}$ is the total number of students in section 4 . We also define $y_{j} \forall j=1 \ldots n_{y}$ where $y_{j}$ is the score obtained by a student $j$ in any other section $(1,2$ or 3$)$ on the same test and $n_{y}$ is the total number of students in that section $\left(n_{x}>=<n_{y}\right)$.

Then we stack the values $x_{i}$ and $y_{j}$ to form a variable $z_{k}$ such that $k=1 \ldots\left(n_{x}+n_{y}\right)$. We also create a dummy variable $d_{k}$ such that $d_{k}=1$, if $z_{k}=x_{i}$ for any $i, k$ (i.e. score belongs to a student in section 4) and zero otherwise (i.e. when the score belongs to a student in the other section). We run the following regression:

$$
z_{k}=\hat{\beta}_{0}+\hat{\beta}_{1} d_{k}+\hat{u}_{k}
$$

Where $\hat{\beta}_{0}$ is the estimate of the intercept and $\hat{\beta}_{1}$ is the estimate of slope (or coefficient of the dummy variable). $\hat{u}_{i}$ is the residual. Here the coefficient $\hat{\beta}_{1}$ will be the difference and it will also have a standard error and test statistics as desired.

\section{Results and Discussion}

Averages of total score obtained by the students in each of the four class sections are in Table 1. These averages indicate that although the flipped section obtained greatest class total among all four sections, results on the tests are not significantly different from traditional sections. A two sample mean comparison test yields that the average course total obtained by the students of the flipped class section is significantly greater than the students of one of the conventional class sections, but not the other two. This could be due to small sample size. These results are summarized in Table 2.

Table 1. Class Average of the Total Score Obtained in the Course (Maximum 100, standard deviation in parenthesis) for Sections 1, 2 and 3 (MWF) and Section 4 (TR)

\begin{tabular}{ccc}
\hline Class Section & Average of total score obtained by students & standard deviation \\
\hline 1 & 82.43 & 9.82 \\
2 & 78.81 & 14.12 \\
3 & 80.57 & 10.00 \\
4 & 83.93 & 10.43 \\
\hline
\end{tabular}

Table 2. Two-Sample Mean Comparison Test for Class Average of Total Score Obtained in the Course for Sections 1, 2 and 3 (MWF) and Section 4 (TR)

\begin{tabular}{cccrr}
\hline & Difference of mean $^{\#}$ & Standard error & t-statistic & p-value \\
\hline Class Section 3 and 4 & 3.364 & 2.705 & 1.243 & 0.109 \\
Class Section 2 and 4 & $5.123^{*}$ & 3.103 & 1.651 & 0.051 \\
Class Section 1 and 4 & 1.497 & 2.627 & 0.570 & 0.285 \\
\hline$* * * 005, * p<0.1$ & & & &
\end{tabular}

$* * * \mathrm{p}<0.001, * * \mathrm{p}<0.05, * \mathrm{p}<0.1$
"Positive difference indicates the score for Section 4 is greater

When we compare the class averages in the two mid-term exams, we find that the flipped class section outperforms two 
of the traditional class sections but not the third in MT1. We do not find a statistically significant difference in average scores for MT2 across different sections. These results are summarized in Table 5. The class average of the flipped section was among the top two sections for the two mid-terms combined and was the third best for the final exam (Table 3). The class average increased from $73 \%$ (MT1) to $77 \%$ (MT2) to $78 \%$ (Final). Similarly, students in two other class sections taught using the traditional style also improved their class averages (Table 4). One traditional class section outperforms the flipped class section with $57.1 \%$ students obtaining a score greater than or equal to $89 \%$. Hence, we can say that there is no conclusive difference between the performance in tests.

Table 3. Class Average and standard deviation (SD) for Midterm Exam 1 (MT1), Midterm Exam 2 (MT2) and Final Exam (Final) Sections 1, 2 and 3 (MWF) and 4 (TR)

\begin{tabular}{lclcccccl}
\hline Class Section & 1 & SD & 2 & SD & 3 & SD & 4 & SD \\
\hline MT1 (Max: 30) & 21.23 & 2.93 & 20.28 & 3.16 & 22.81 & 3.00 & 21.93 & 5.54 \\
\hline MT2 (Max: 30) & 24.03 & 3.91 & 22.23 & 4.61 & 23.40 & 4.55 & 23.03 & 3.44 \\
\hline Final (Max: 40) & 32.85 & 6.48 & 31.50 & 9.19 & 29.92 & 7.23 & 31.10 & 7.19
\end{tabular}

Table 4. Class Average in Percent for Midterm Exam 1 (MT1), Midterm Exam 2 (MT2) and Final Exam (Final) Sections 1, 2 and 3 (MWF) and 4 (TR)

\begin{tabular}{rcccc}
\hline Class Section & 1 & 2 & 3 & 4 \\
\hline MT1 (\%) & 70.77 & 67.60 & 76.03 & 73.10 \\
MT2 (\%) & 80.10 & 74.10 & 78.00 & 76.77 \\
Final (\%) & 82.13 & 78.75 & 74.80 & 77.75 \\
\hline
\end{tabular}

Table 5. Two-Sample Mean Comparison Test (difference of mean) for Class Average of Midterm 1 (MT1), Midterm 2 (MT2) and Final Exam Score Obtained and Standard Error (SE) in the Course for Sections 1, 2 and 3 (MWF) and Section 4 (TR)

\begin{tabular}{lclclcl}
\hline & MT1 & SE & MT2 & SE & Final Exam & SE \\
\hline Section 4 and 3 & -0.183 & 0.942 & -0.367 & 1.078 & 1.178 & 1.903 \\
Section 4 and 2 & $2.343^{* *}$ & 0.897 & 1.502 & 1.253 & -0.398 & 2.063 \\
Section 4 and 1 & $1.625^{*}$ & 0.905 & -1.002 & 0.965 & -1.756 & 1.777
\end{tabular}

$* * * \mathrm{p}<0.001,{ }^{* *} \mathrm{p}<0.05,{ }^{*} \mathrm{p}<0.1$

However, in line with current research, what is evident from observing the progress of the flipped class, is that the class as a whole achieved much more in terms of breadth and depth of the subject as compared to the traditional class sections. This was evident through the student team-based research projects. The research projects included an analysis of the financial statements of Southwest and other low-cost passenger airlines, Nike, Tesla and GoPro. Two of these research projects were showcased at the "Undergraduate Research Colloquium" at the college. One research project was presented at the university's undergraduate student research poster presentation event called the Discovery Day.

The only quantifiable benefit of the flipped method of learning was that the class afforded enough time for all the students participate and easily complete their research projects. Besides spending time on research, the students of the flipped class successfully participated in 32 graded quizzes and the average score on these quizzes was $96.5 \%(0.31)$. On average, a typical student did approximately $80 \%$ of all assigned online quizzes. Students in the flipped section were surveyed using extra questions in the university's end-of-semester evaluation. In these surveys, they mentioned that the class was hands-on (figure 1) and yet it helped them learn at their own pace (figure 1 and 2). 


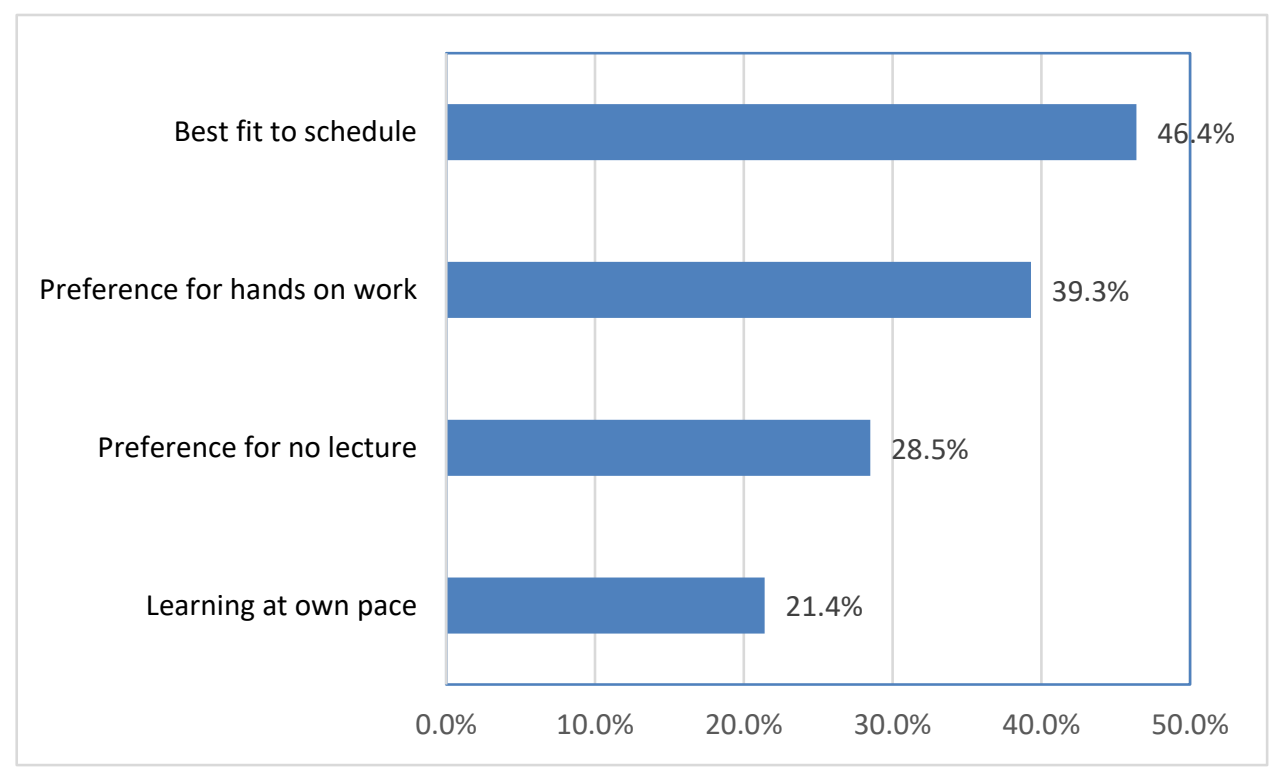

Figure 1. Survey on the Main Reason(s) for Continuing in the Flipped Class

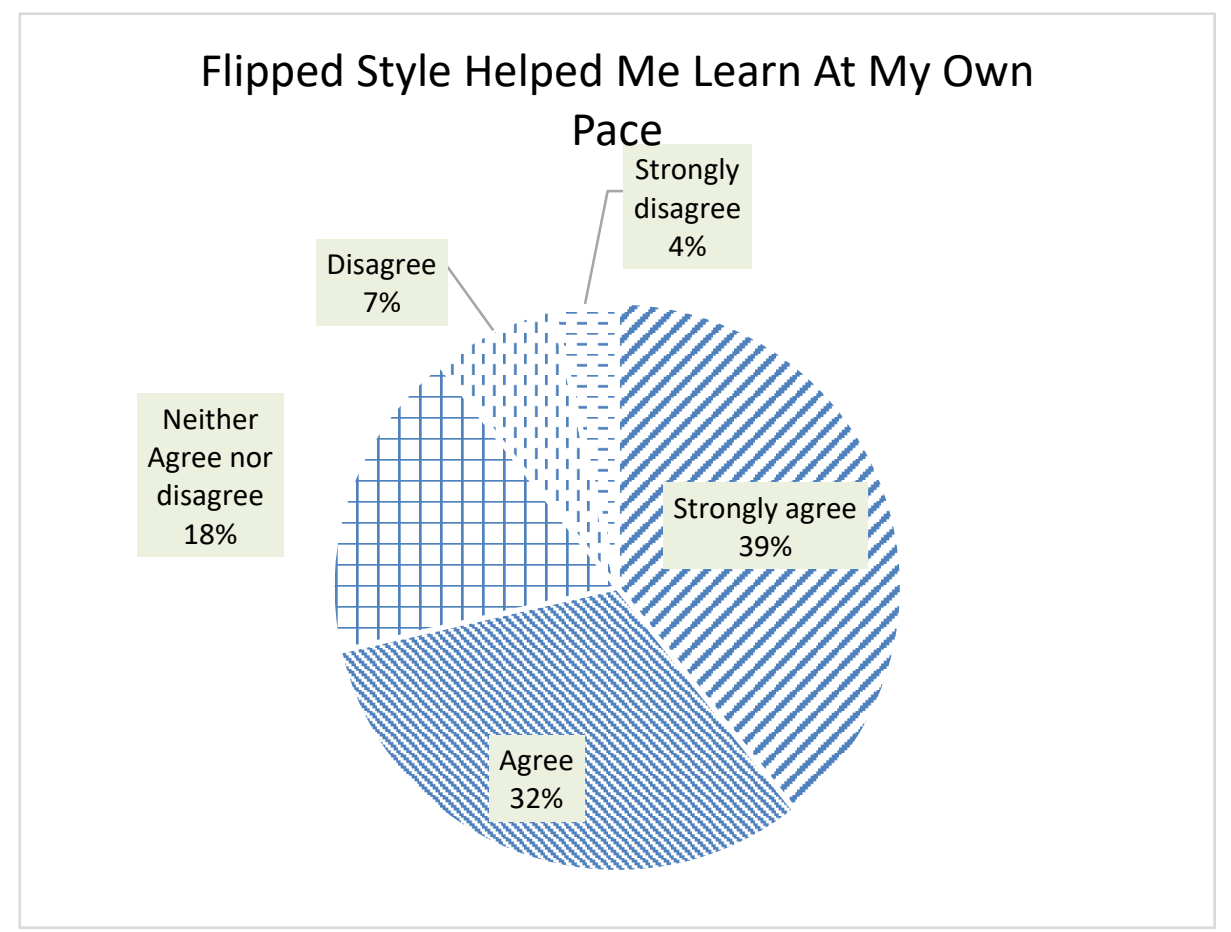

Figure 2. Survey about Learning in the Flipped Classroom at Own Pace

An overwhelming majority of students $(95.5 \%)$ in the flipped class section were satisfied with the instruction in the course as reported through student evaluations to the university. When asked why students chose to stay with the flipped section of the class, one major reason for students to continue with the class was schedule requirement (Figure 1). 


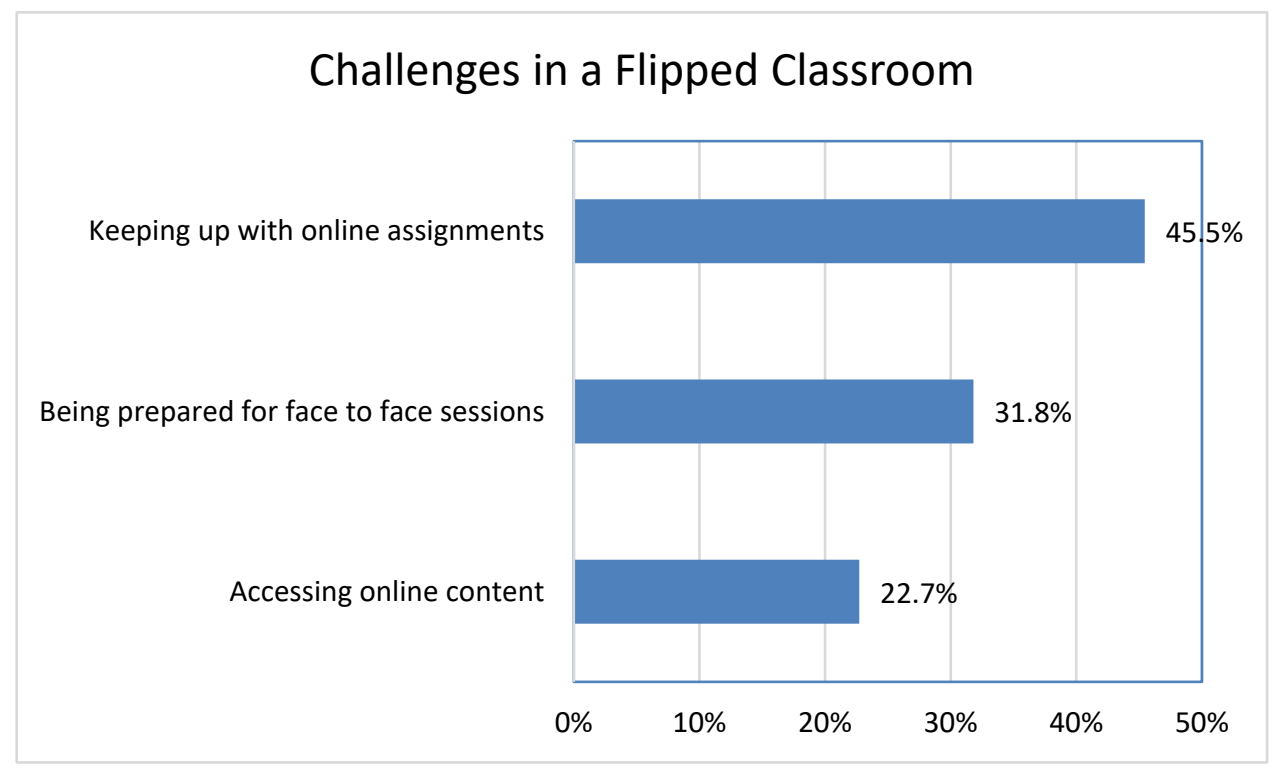

Figure 3. Challenges in Learning in the flipped classroom

However, many students reported that they continued with the class because they felt the class would be more hands on than the traditional format would allow. Majority $(71 \%)$ of the students agreed that flipped class helped them learn the course content at their own pace (Figure 2). Even though the biggest challenge faced by students in the flipped classroom was the number of online quizzes and assignments (Figure 3), a majority of the students felt that both lectures and online quizzes were helpful for the flipped class (Figure 4).

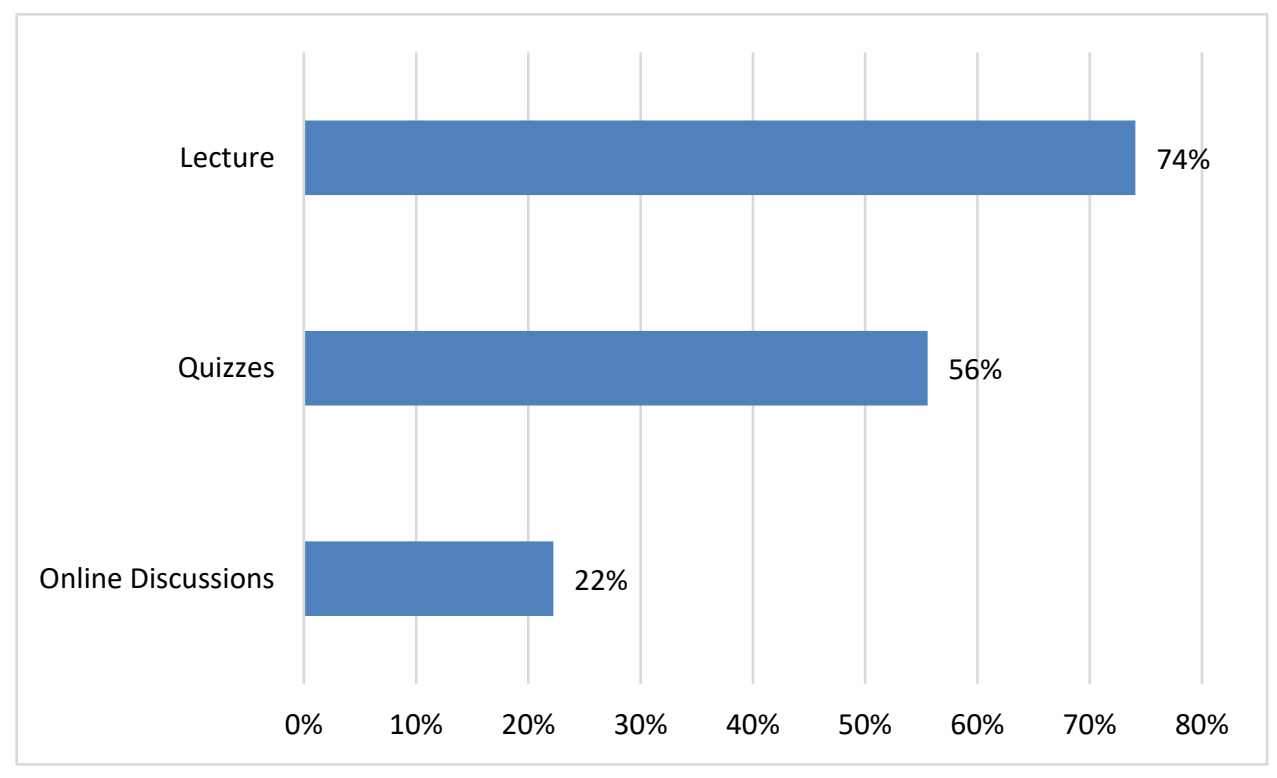

Figure 4. Most Suitable Components that can be Flipped

The data analyses discussed from figures 1 - 4 are consistent with the qualitative comments made by the students in the anonymous end-of-the-semester course evaluation. One student states,

"The online videos posted were very helpful in preparing me for the class. Also, the review sessions given before the test, sample test included. And the enthusiasm while teaching kept me engaged in learning. The group work really helped keep the class engaged as well!"

Another student agrees, 
"The activities and the quizzes were the most helpful to teach the material. Both of those were helpful because they laid out the objectives for each chapter and what would be most important to learn."

This seems to be in agreement with the overall objective of a flipped class that students make connections with the bigger picture of the course better when they are prepared before the class. Other students also agree with the concept.

"The video lectures the Professor posted helped me further understand the material as I could go back through the material with the click of a mouse."

"Online lectures were amazing. Please do it for every class in the school."

By the end of the semester the students became so independent in learning the concepts of the lecture by themselves that when asked in the same end of the semester evaluation, their biggest issue with the element of the class that least helped them were some of the last few quick lectures in class. One student states,

"The teacher's presentation was an element of the class that least helped them."

Finally, one student summarizes the workload of a flipped class with the following statement,

"If you added more of an online aspect I do not feel like it would have been as successful. There was not an overload of online or out of class assignments so it helped students to actually participate. I did not mind having to listen to a few online lectures but more than one or two a week would have made me less successful."

\section{Concluding Remarks and Pedagogical Implications}

Flipped style of learning is significant because it allows students to prepare for in-person work at home, at their own pace and convenience. This is particularly relevant in the current environment when there is greater emphasis on self-study and student motivation. Theory of learning suggests that if students are entrusted with greater responsibility and ownership of at least partially setting their own goals within a course, they usually live up to that role successfully. Several studies on collaborative and active learning have repeatedly emphasized this fact. This study attempts to investigate whether students in a flipped class performed better in terms of responsibility, ability to produce better test scores and ability to deliver. This is significant because it adds to the existing literature by providing a perspective in the field of finance, which can be either more theoretical or more relevant to the real world depending on the student-instructor perspectives. Few studies in finance have shown importance of case studies and student awareness of problems in the real world. This study takes a step further. It allows students to not only learn what is conventionally taught in Finance, but it also provides an infrastructure to create and analyze their own real-world problem through a class project.

Students in a flipped class need to be better prepared for the class session than the traditional class. It can be occasionally difficult for learners to find enough motivation to go through a new topic on their own. However, it is the instructor's job to motivate students by providing a background on new subject matter. Evidence suggests that instructors using the flipped format can either introduce the idea in previous class, or enforce a graded component of evaluation associated with the preparation activity (such as an assessment quiz). This motivates students to get organized and ready for class. Online lectures are distinctly useful because the students can learn at their own pace and be prepared for in-depth applications. In the classroom, there is more time for hands-on problem solving and other synthesizing activities such as research projects.

Pedagogical implications of this study indicate that instructors need to motivate students to be prepared to take larger responsibility of their learning. They need to motivate students to be ready to know what needs to be done at their convenience and in what order. Faculty need to motivate students to see the end goals of what can be achieved if this style is followed properly. Students need to be prepared to actively seek direction when there are doubts and the path is not clear. When assigned work is completed on schedule, it opens the door to cognitive learning in the classroom. Students can collaborate in achieving higher order learning outcomes, first by helping each other through mutual cooperation in assimilation of concepts and second by solving problems using inductive and deductive reasoning. Faculty need to direct classroom discussion and ensure secondary benefits of concept building. Thus, classroom time needs to be utilized in activities and applied research projects. The focus shifts from instruction of terms and definitions to discussion of concepts and inquiry-based analysis of problems through active learning styles. This allows greater connection between student learning outcomes and pedagogical design with the caveat that not all students will necessarily be on board.

This study of flipped style of instruction allowed close monitoring of all the above characteristics. However, it is important to note that students who are more comfortable with in-class lectures can sometimes struggle (often early-on) 
with this kind of instruction technique. Prior review of lecture and theoretical concepts are expected to help classroom activities. In this study, students in the flipped class were engaged at a deeper level in these activities; which may help them produce higher order thinking skills such as analyzing and synthesizing the concepts, particularly when working on research projects. Since student intellect is an exogeneous variable, it is expected that student performance on tests is hard to predict, which is captured in this study by the residual in the two-sample unpaired mean comparison test. When this is coupled with small sample size, it leads to lack of statistical significance Consequently, one observation from this study is that student performance on tests in flipped class is not significantly better from the that in traditional classroom. However, going through student feedback and review of their own account of learning in the flipped format is encouraging. This is noticeable when students explicitly state that they realized their potential in their ability to learn by doing hands-on work such as deep application activities and real-world projects. All this should give enough motivation to other instructors to try this method in their class.

\section{Acknowledgements}

The author would like to thank Kathryn Cunningham for helpful comments and contributions to an earlier version of this paper, and to the Center for Teaching and Learning Excellence at Embry-Riddle Aeronautical University for insightful discussions on the subject.

\section{References}

Ağirman, E., \& Trinh, C. (2019). The Flipped Learning Approach in Undergraduate Finance Education: A Literature Review. Atatürk Üniversitesi İktisadi ve İdari Bilimler Dergisi,33(4), 1367-1381. https://doi.org/10.16951/atauniiibd.616083

Alan Eager, E., Peirce J., \& Barlow P. (2014). Math Bio or Biomath? Flipping the mathematical biology classroom. Letters in Biomathematics, 1(2), 139-155. https://doi.org/10.1080/23737867.2014.11414476

Ambrose, S. A., Bridges, M. W., DiPietro, M., Lovett, M. C., \& Norman, M. K. (2010). How Learning Works: Seven Research-Based Principles for Smart Teaching. San Francisco: Jossey-Bass.

Andreychik, M. R., \& Martinez, V. (2019). Flipped vs. Traditional: An Analysis of Teaching Techniques in Finance and Psychology. Teaching \& Learning Inquiry, 7(2), 154-167. https://doi.org/10.20343/teachlearninqu.7.2.10

Bates, S., \& Galloway, R. (2012). The inverted classroom in a large enrolment introductory physics course: A case study, The Higher Education Academy.

Bergmann J., \& Sams, A. (2009). Remixing chemistry class: Two color-ado teachers make vodcasts of their lectures to free up class time for hands-on activities, Learning \& Leading with Technology, 36(4), 22-27.

Berrett, D. (2012). How 'flipping' the classroom can improve the traditional lecture. The Chronicle of Higher Education, $12,1-14$

Bishop, J. L., \& Verleger, M. A. (2013). The flipped classroom: A survey of the research. ASEE National Conference Proceedings, Atlanta, GA, 30(9).

Bligh, D.A. (2000). What's the use of lectures? San Francisco: Jossey-Bass.

Bloom, B. S. (Editor), Engelhart M. D. (Author), Hill W. H. (Editor), Furst E. J. (Editor), Krathwohl, D. R. (1956). Taxonomy of educational objectives: Vol. 1: Cognitive Domain, New York: McKay.

Brealey, R. A., Myers, S. C., \& Marcus, A. (1995). Fundamentals of Corporate Finance, McGraw Hill Education, $7^{\text {th }}$ edition.

Butt, A. (2014). Student views on the use of a flipped classroom approach: Evidence from Australia. Business Education \& Accreditation, 6.1, 33-43.

Crouch, C. H., \& Mazur, E. (2001). Peer instruction: Ten years of experience and results. American journal of physics, 69(9), 970-977. https://doi.org/10.1119/1.1374249

Dahlstrom, E., \& Bichsel, J. (2014). ECAR Study of undergraduate students and information technology, 2014. Research report. Louisville, CO: ECAR. Available from http://www.educause.edu/ecar, Accessed 10-18-2016.

Fendler, R. J., Ruff C., \& Shrikhande, M. (2011). Online versus in-class teaching: Learning levels explain student performance. Journal of Financial Education, 45-63.

Findlay-Thompson, S., \& Mombourquette, P. (2014). Evaluation of a flipped classroom in an undergraduate business course. Business Education \& Accreditation, 6 (1), 63-71.

Hao, Y. (2016). Exploring undergraduates' perspectives and flipped learning readiness in their flipped classrooms. Computers in Human Behavior, 59, 82-92. https://doi.org/10.1016/j.chb.2016.01.032 
Kaner, C., \& Fielder, R. L. (2005). Inside out: A computer science course gets a makeover. The National Convention of the Association for Educational Communications and Technology, 2, 254-264.

Lage, M. J., Platt, G. J, \& Treglia, M. (2000). Inverting the classroom: A gateway to creating an inclusive learning environment. The Journal of Economic Education, 31(1), 30-43. https://doi.org/10.1080/00220480009596759

Lape, N. K., Levy, R., Yong, D. H., Haushalter, K. A., Eddy, R., \& Hankel, N. (2014). Probing the inverted classroom: A controlled study of teaching and learning outcomes in undergraduate engineering and mathematics. 24(1006), 1-21.

Mason, G. S., Shuman, T. R., \& Cook, K. E. (2013). Comparing the effectiveness of an inverted classroom to a traditional classroom in an upper-division engineering course, IEEE Transactions on Education, 50(4), 430-435. https://doi.org/10.1109/TE.2013.2249066

Mazur, E. (2009). Farewell, lecture, Science, 323(5910), 50-51. https://doi.org/10.1126/science.1168927

Moravec, M., Williams, A., Aguilar-Roca, N., \& O'Dowd, D. K. (2010). Learn before lecture: a strategy that improves learning outcomes in a large introductory biology class. CBE-Life Sciences Education, 9(4), 473-481. https://doi.org/10.1187/cbe.10-04-0063

Mu, H., \& Paparas, D. (2016). Ready for the Flipped Classroom? Preliminary experiences of the new approach in teaching economics to non-major students, Applied Economics and Finance, 3(2), 45-53. https://doi.org/10.11114/aef.v3i2.1288

Psihountas, D. (2018). Flipped Classrooms and Finance-Is this a Better Way to Learn? Journal of Financial Education. 44(1), 1-11.

Sophia, (2014). Flipped Classroom Survey, http://www.sophia.org/flipped-classroom-survey, Accesed -10-08-2014.

Talbert, R. (2014). Inverting the linear algebra classroom. Primus, 24(5), 361-374. https://doi.org/10.1080/10511970.2014.883457

Toto, R., \& Nguyen, H. (2009). Flipping the work design in an industrial engineering course. Frontiers in Education Conference, 1(4), 39th IEEE, IEEE 2009. https://doi.org/10.1109/FIE.2009.5350529

Vazquez, J. J., \& Chiang, E. P. (2015). Flipping out! A case study on how to flip the principles of economics classroom. International Advances in Economic Research, 21(4), 379-390. https://doi.org/10.1007/s11294-015-9549-5

\section{Copyrights}

Copyright for this article is retained by the author(s), with first publication rights granted to the journal.

This is an open-access article distributed under the terms and conditions of the Creative Commons Attribution license which permits unrestricted use, distribution, and reproduction in any medium, provided the original work is properly cited. 